\title{
El desvanecimiento del blindaje de defensa de Bolivia en Arbitrajes Internacionales de Inversión
}

\author{
Andrés Moreno Gutiérrez
}

\begin{abstract}
SUMARIO
1. Reformas estructurales en Bolivia. 2. El proceso de capitalización de Entel S.A. 3. La nacionalización del paquete accionario de ETI EUROTELECOM INTERNATIONAL en Entel S.A. 4. El Arbitraje Internacional de Inversiones de ETI contra el Estado boliviano. 5. Desistimiento de ETI ante el CIADI: Sometimiento de las partes a CNUDMI. 6. La estrategia de defensa del Estado Boliviano: Denuncia de la Convención de Washington 7. Desvanecimiento del principal blindaje de defensa de Bolivia. 8. Vigencia y eficacia de los 22 BITs suscritos por Bolivia.
\end{abstract}

\section{Reformas estructurales en Bolivia}

Luego de afrontar el proceso inflacionario más impactante que hubiera registrado la historia del mundo moderno, Bolivia se vio en la necesidad de adoptar una serie de reformas estructurales que comenzaron a vislumbrarse con la aprobación del polémico Decreto Supremo No. 21060 de 29 de agosto de 1985, el cual permitiría la implantación de una nueva política económica a través de la transición de un agotado modelo de Estado protagonista de los más importantes sectores de la economía,

1. Abogado - socio de Moreno Baldivieso Estudio de Abogados de La Paz, Bolivia. 
hacia un modelo de Estado donde primaría una economía de libre mercado caracterizada por su apertura favorable a inversionistas extranjeros.

Dichas reformas de corte estructural serían profundizadas a lo largo de la década de los '90 mediante la implementación del denominado proceso de capitalización ${ }^{2}$, que vino a constituir el modelo boliviano de privatización de empresas públicas. De esta manera, el país consolidaría el tránsito de un Estado Intervencionista a un Estado Regulador que con esta nueva política económica cedía las actividades económicas tradicionalmente desarrolladas por el sector público al sector privado.

El proceso de capitalización tuvo como propósito principal reestructurar los sectores de electricidad, hidrocarburos, telecomunicaciones, transportes y fundición, en procura de reducir la pesada burocracia así como también el marcado índice de subordinación política a la cual se veían sometidas las administraciones de las empresas de dichos sectores, las mismas que mediante este mecanismo, podrían elevar su competitividad para actuar en mercados de escala.

El sustento jurídico de la capitalización quedó configurado en la Ley No. 1544 de 21 de marzo de 1994, Ley de Capitalización, la misma que inicialmente autorizó la conversión de las principales empresas estatales ${ }^{3}$ de Bolivia en sociedades de economía mixta ${ }^{4}$, para posteriormente incrementar el capital de estas empresas mediante aportes de inversores privados nacionales o extranjeros, con la consiguiente emisión de acciones ordinarias representativas de dichos aportes.

2. La capitalización, a diferencia del proceso de privatización puro y simple, se caracterizaba porque la totalidad del aporte del inversor seria destinado a incrementar el capital de la empresa involucrada en el proceso de capitalización, permitiendo su recstructuración.

3. Las principales empresas de Bolivia y que fucron sometidas a proceso de capitalizaciỏn son: Yacimicntos Petroliferos Fiscales Bolivianos (YPFB), Empresa Naciona! de Electricidad (ENDE), Empresa Nacional de Tejecomunicaciones (ENTEL), Empresa Nacional de Ferrocarriles (ENFE) y Empresa Metalürgica Vinto.

4. La sociedad anónima mixta (SAM) es una sociedad que se encuentra regulada por fos articulos 424 del Código de Comercio de Bolivia, y su capital social resulta de la conjugación del capital estatal y el capital privado. 
Adicionalmente, con la finalidad de optimizar el proceso de capitalización, y mejorar las posibilidades de atracción de inversiones, la Ley de Capitalización dispuso que los pasivos de las sociedades sujetas a capitalización pudieran ser transferidos ya sea de manera parcial o total al Tesoro General de la Nación que en última instancia absorbería las pérdidas que el ejercicio deficitario de algunas empresas hubiera acumulado durante años de gestión deficiente en muchos casos.

\section{El proceso de Capitalización de Entel S.A.}

Naturalmente y como no podía ser de otra manera, la Empresa Nacional de Telecomunicaciones (Entel) -que en ese entonces se constituía en la primera y única dedicada a la telefonía de larga distancia, conexiones internacionales, etc. con un mercado cautivo del $60 \%$ de las telecomunicaciones- vino a formar parte del conglomerado de empresas estatales que serían sometidas al novedoso proceso de capitalización que se presentaba prometedor para revitalizar y dar un nuevo empuje a la economía boliviana.

Como quiera que el marco legal establecido señalaba que el inversor nacional o extranjero debía ser seleccionado mediante proceso de Licitación Pública Internacional, el Gobierno Boliviano emitió la correspondiente convocatoria dirigida a inversores que estuvieran interesados en capitalizar Entel. En dicha Licitación participaron ocho compañías preseleccionadas: Bell Atlantic International, France Telecom, Stet International NV (Stet), Telephone International of Spain, Korea Telecom, Marconi, MCI International y Sprint International.

Las ofertas finales para capitalizar Entel llegaron de Telephone International of Spain que ofertó US\$ 162.5 millones, MCI International US $\$ 303$ millones, mientras que la mejor oferta provino de Stet que ofreció US\$ 610 millones, resultando en consecuencia esta última empresa adjudicataria del $50 \%$ de las 
nuevas acciones ordinarias de Entel, la misma que como producto del proceso de capitalización, se transformó en un primer momento de empresa pública a sociedad de economía mixtas, siguiendo los lineamientos marcados por la Ley de Capitalización.

A efectos de viabilizar la emisión de acciones, el 27 de noviembre de 1995 el Estado de Bolivia y Stet firmaron un Contrato de Suscripción de Acciones en cuyo mérito Stet se obligó a efectuar la inversión comprometida, constituyéndose en virtud de este mismo Contrato un fondo de reserva por concepto de prima de emisión.

Como producto de la capitalización, el $50 \%$ de las acciones de Entel quedaron en propiedad de Stet, el 3\% de las acciones fueron destinadas a los trabajadores de Entel en calidad de compensación por sus beneficios sociales, en tanto que el $47 \%$ restante sería transferido a los ciudadanos bolivianos residentes en el país que al 31 de diciembre de 1995 hubieran alcanzado la mayoría de edad', estando la administración de este $47 \%$ de acciones a cargo de las Administradoras de Fondos de Pensiones "Futuro de Bolivia S.A. AFP" y "BBVA Previsión AFP S.A.", conforme se muestra en el siguiente gráfico.

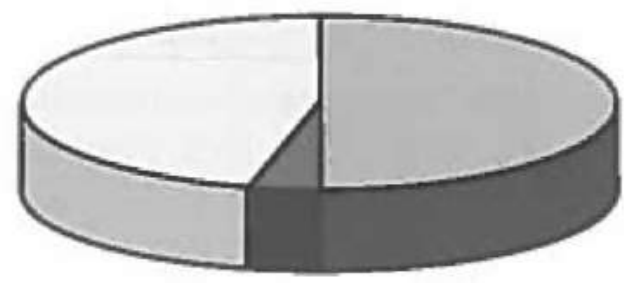

\section{STET INTERNATIONAL}

TRABAJADORES

CIUDADANOS BOLIVIANOS

5. Eventualmente y como producto de una serie de reestructuraciones internas, Entel se transformaria en una sociedad anónima sujeta al régimen privado contenido fundamentalmente en el Código de Comercio de Bolivia. A partir de ese entonces, la denominación de Entel seria Empresa Nacional de Telccomunicaciones S.A. - ENTEL S.A.

6. De acueruo al articulo 4 del Código Civil vigente en 1995, la mayoria de edad se alcanzaba a los 21 años. 


\section{La NACIONALIZACIÓN DEL PAQUETE ACCIONARIO DE ETI EUROTELECOM INTERNATIONAL EN ENTEL S.A.}

El proceso de nacionalización que viene implementando el Estado boliviano comenzó el año 2006, con la promulgación del Decreto Supremo No. 28701 de 1 de mayo de ese año, denominado "Héroes del Chaco" en remembranza de los caídos en el conflicto bélico que se suscitara entre Bolivia y Paraguay en la década de los '30, precisamente en la región del Chaco que actualmente posee los mayores reservorios hidrocarburíferos descubiertos en nuestro país.

Con el Decreto señalado en el párrafo anterior, el Estado nacionalizó las acciones necesarias para que Yacimientos Petrolíferos Fiscales Bolivianos ${ }^{7}$ controle como mínimo el $50 \%$ más 1 en las empresas Chaco S.A., Andina S.A., Transredes S.A., Petrobras Bolivia Refinación S.A. y Compañía Logística de Hidrocarburos de Bolivia S.A.

Transcurridos dos años, en el marco de este proceso constante y progresivo de nacionalización, el Gobierno de Bolivia decretó la nacionalización del paquete accionario perteneciente a ETI en Entel, surgiendo a raíz de esta medida el diferendo entre el Estado Boliviano y la sociedad ETI EUROTELECOM INTERNATIONAL NV $(E T T)^{8}$, subsidiaria de la firma Telecom Italia NV $^{9}$ que a su vez viene a ser la principal compañía holding de Telecom Italia S.p.A.

La estructura de titularidad de las acciones de ETI es compleja y puede explicarse de mejor manera a través del siguiente cuadro que muestra su estructura corporativa:

7. Yacimientos Petroliferos Fiscales Bolivianos es la empresa estatal encargada de dirigir y administrar las actividades hidrocarburiferas de upstream y downstream.

8. ETl es una compañia pública de responsabilidad limitada (Naantlnze Ventootschap) incorporada bajo las Leyes del Reino de los Paises Bajos.

9. Stet International NV pasó a Telecom Jtalia NV, de cuya consecuencia esta última empresa se hizo titular del $50 \%$ del paquete accionario de Entel a través de su subsidiaria ETI EUROTELECOM INTERNATIONAL NV. 


\section{Estructura corporativa de ETI}

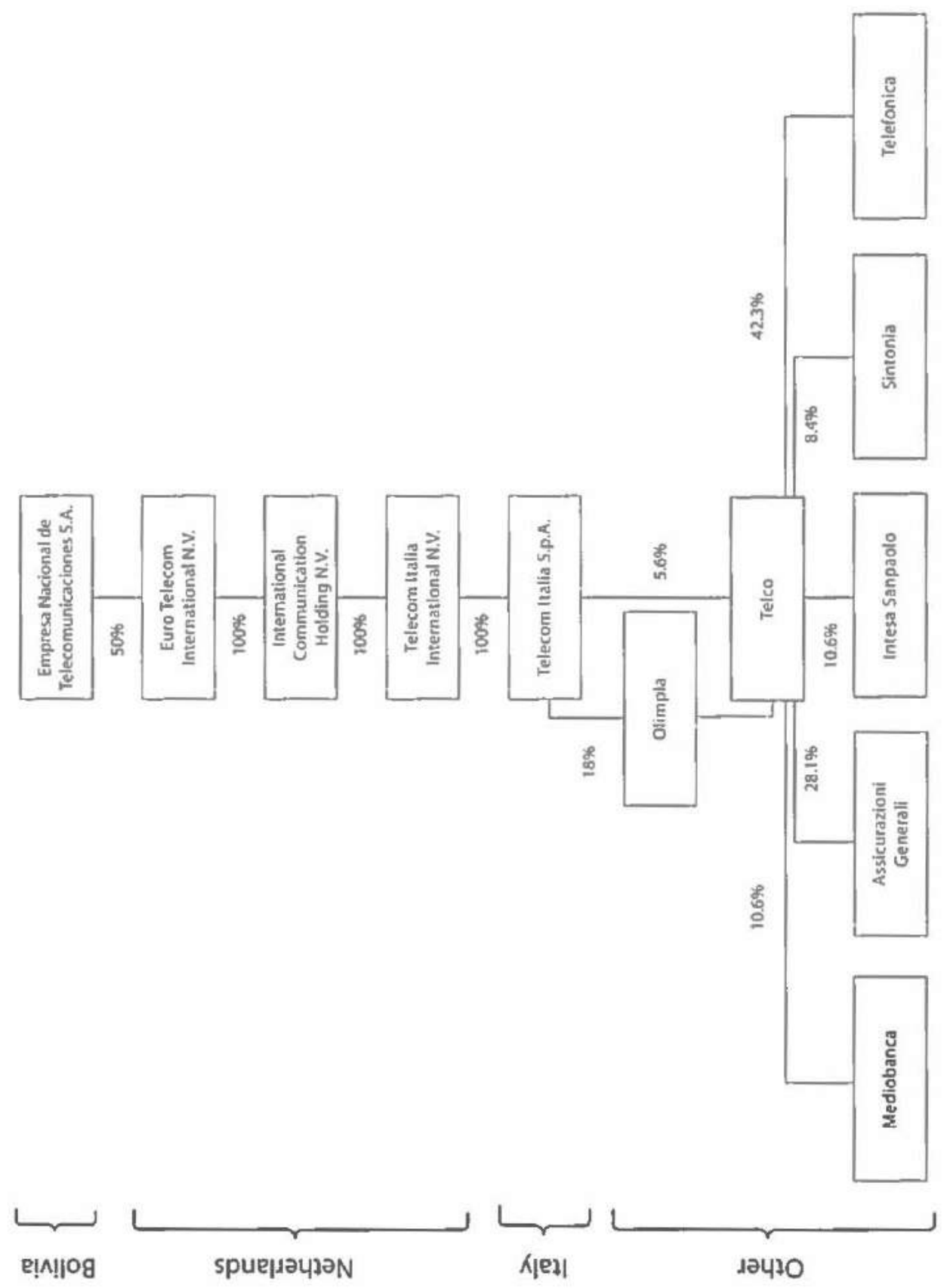

Fuente:

http://www.cadtm.org/IMG/pdf/ICSID_TI_Hands_off_Bolivia.pdf 
Como medida previa a la nacionalización efectiva del paquete accionario de ETI, mediante Decreto Supremo No. 29101 de 23 de abril de 2007, el Gobierno dispuso la transferencia en favor del Estado boliviano, a título gratuito, de las acciones de los ciudadanos bolivianos que formaban parte del Fondo de Capitalización Colectiva en ENTEL S.A., administradas por las Administradoras de Fondos de Pensiones "Futuro de Bolivia S.A. AFP" y "BBVA Previsión AFP S.A.".

La nacionalización en cuestión fue dispuesta por el Gobierno del Presidente Evo Morales en virtud del Decreto Supremo No. 29544 aprobado en fecha 1 de mayo de 2008, después de que hubieran fracasado las gestiones llevadas adelante por una Comisión Ad hoc ${ }^{10}$-conformada en marzo de 2007-con el propósito especial de negociar con los representantes acreditados de ETI los términos para una posible salida amistosa de dicha empresa, con la consiguiente recuperación del $50 \%$ de las acciones de Entel a favor del Estado.

El Decreto Supremo referido en el párrafo anterior, señala que como efecto de la nacionalización, ETI recibiría el valor de sus acciones como justa indemnización, para lo cual debió haberse llevado a cabo un proceso de valuación en un plazo de 60 días. Adicionalmente, el Decreto dispuso que del pago a efectuarse a ETI se descontarían los pasivos financieros, tributarios, laborales, comerciales y regulatorios de Entel, de la misma manera que éstos fueron absorbidos por el Tesoro General de la Nación a tiempo de la capitalización.

\section{El Arbitraje Internacional de InVersiones DE ETI CONTRA EL ESTADO BOLIVIANO}

Ante las medidas expropiatorias dispuestas por el Gobierno boliviano, y toda vez que no pudo establecerse ningún consenso

10. La Comisión Ad hoc comisionada para negociar la compra consensuada del paquele accionario de ETI en Bolivia se instituyó en mérito al Decreto Supremo No. 29087 de 28 de marzo de 2007. 
pacífico sobre la indemnización que debía hacerse efectiva a favor de ETI, el 12 de octubre de 2007, la solicitud de arbitraje" fue presentada por dicha empresa ante el Secretario general del Centro Internacional de Arreglo de Diferencias relativas a Inversiones (CIADI).

La solicitud de arbitraje fue posterior a una Carta de 27 de abril de 2007 que ETI habría enviado al Estado boliviano, argumentando la vulneración de los estándares de protección establecidos por el Tratado Bilateral de Protección y Promoción Recíproca de Inversiones (BIT) entre Bolivia y el Reino de los Países Bajos.

Según lo sostenido por ETI, tanto a través de la Carta de 27 de abril de 2007 como así también a través de la solicitud de arbitraje de 12 de octubre de 2007, dicha sociedad habría expresado y perfeccionado su consentimiento para someterse al CIADI, aceptando de esta manera la invitación u oferta abierta del Estado Boliviano a someter cualquier disputa internacional sobre inversiones ante dicho Centro, conforme a los propios términos previstos en el BIT entre Bolivia y el Reino de los Países Bajos.

De acuerdo con informaciones de personeros de Gobierno, la cuantía reclamada por ETI en este proceso arbitral ante el CIADI sería de US $\$ 350$ millones.

\section{Desistimiento de ETI ANTE el CIADI: SOMETIMIENTO DE LAS PARTES A CNUDMI}

El 16 y 20 de octubre de 2009 respectivamente, la ex Ministra de Defensa Legal del Estado, Cecilia Rocabado Turbet, habría acordado y firmado con ETI un "Acuerdo de Arbitraje Ad Hoc" y un "Acuerdo Complementario de Arbitraje Ad Hoc", por cuya

11. La solicitud de arbitraje se denomina en inglés Request for Arbitration. 
virtud se habría establecido que ETI desistiría del proceso instaurado ante el CIADI y que por consiguiente tanto el Estado como ETI se someterían a un procedimiento arbitral internacional sobre inversiones, bajo las reglas de la Comisión de las Naciones Unidas para el Derecho Mercantil Internacional (CNUDMI), haciendo renuncia expresa a la posibilidad de objetar la jurisdicción del tribunal arbitral ad hoc que actualmente conoce de este arbitraje.

Con estos Acuerdos, la ex Ministra anunciaría que Bolivia tendría ganada su primera Batalla, debido a que en su criterio Bolivia se habría liberado del CIADI en el caso particular de ETI; sin embargo, contrastando la alegoría de dichas declaraciones, el descontento a nivel gubernamental fue generalizado, puesto que la defensa de Bolivia, hasta ese momento, se había enfocado principalmente en argumentar la falta de jurisdicción del CIADI, habiéndose traducido esta reticencia desde un inicio a través de la solicitud efectuada por Bolivia para que el CIADI rechace el caso por la supuesta manifiesta falta de jurisdicción de dicho Centro'2.

\section{LA ESTRATEGIA DE DEFENSA DEL ESTADO BoliviANO: Denuncia de la Convención de Washington}

El Estado boliviano fue consciente en todo momento que el programa escalonado de nacionalizaciones que repetiría año tras año y coincidentemente el 1 de mayo ${ }^{13}$ de cada año, traería aparejado consigo una serie de disputas internacionales con las empresas afectadas que procurarían indemnizaciones prontas y adecuadas, conforme a los estándares de protección contenidos

12. El articulo 36 - 3. de la Convención de Washington seviala que el Secretario general del CIADI debe registrar la solicitud de arbitraje, exceplo si eneuentra que la misma se encuentra manifiestamente fuera de la jurisdicción del Centro.

13. Al igual que lo que ocurre en gran parte del mundo, Bolivia conmemora el 1 de mayo como día del Trabajador en honor a la masacre acaecida en la ciudad de Chicago en el año 1886. 
en los 22 Tratados Bilaterales de Protección y Promoción Recíproca de Inversiones $(B I T s)^{14}$ suscritos y ratificados por el Estado de Bolivia, los mismos que hasta el día de hoy permanecen incólumes en sus términos.

En este sentido, y buscando reducir en cierta medida la exposición estatal frente a foros de arbitraje internacional, Bolivia adoptó como primera salvaguarda de defensa la denuncia del Convenio sobre Arreglo de Diferencias Relativas a Inversiones entre Estados y Nacionales de otros Estados, aprobado en Washington el 18 de marzo de 1965 (Convención de Washington), de tal manera que el CIADI dejara de tener jurisdicción ante los posibles arbitrajes internacionales sobre inversiones que se asomaban al influjo de las medidas expropiatorias asumidas.

Esta denuncia tuvo lugar en fecha 2 de mayo de 2007, haciendo que el retiro de Bolivia del CIADI fuera efectivo 6 meses más tarde, es decir el 3 de noviembre de ese mismo año, previo agotamiento del "cooling off period" establecido por el artículo $71^{15}$ de la Convención de Washington.

\section{DesVanecimiento del PRincipal blindaje DE DEFENSA DE BOLIVIA}

El descontento del Gobierno con los Acuerdos ejecutados por la ex Ministra de Defensa Legal del Estado resultó fundado, y en la práctica anticipaba la formulación de una nueva preten-

14. El Estado de Bolivia viene realizando constantes anuncios respecto a la renegociación de los 22 BITs en los que ha empeñado su fe; sin embargo, hasta donde se conoce, por el momento ningún BIT habria quedado sin efecto o habria climinado al CIADI como entidad con jurisdicción para administrar procesos arbitrales internacionales sobre inversiones cntre Bolivia y nacionales de otros Estados amparados por las garantias que ofrecen los BITs vigentes en Bolivia, y de los cuales, precisamente el cjecutado con Estados Unidos y con el Reino de los Paises Bajos serian los que contienen protecciones màs amplias para los inversores extranjeros.

15. El articulo 71 de la Convención de Washington establece que todo Estado Contratanic tiene la facultad de denunciar el Convenio mediante notificación escrita dirigida al depositario del mismo, tenien. do efecto la denuncia seis meses después de la notificación. 
sión por parte de ETI, en términos que a todas luces serían mucho más gravosos para Bolivia.

En noviembre de 2009, ETI formuló cargos indemnizatorios que alcanzan a 700 millones de euros ${ }^{16}$, es decir que la actual cuantía reclamada se incrementó considerablemente en comparación con la cuantía que involucraba el fallido procedimiento arbitral inicialmente intentado ante el CIADI, sumándose a dicho monto, la pretensión adicional de pago de un interés compuesto con una tasa del $10 \%$.

Quizás Rocabado creyó que logrando el abandono del CIADI demostraría uno de los puntos medulares en los que había insistido la defensa de Bolivia; sin embargo, resulta evidente que la ex autoridad no tomó en consideración ni evaluó en su verdadera dimensión que la resistencia a la jurisdicción del CIADI era tal vez una de las mejores estrategias para prolongar una defensa sustentable que además gozaría del respaldo de CHRISTOPH H. SCHREUER, Profesor de Derecho Internacional en la Universidad de Viena y una autoridad reconocida en la materia.

Bolivia sostenía como principal argumento de defensa que el CIADI carecería de jurisdicción toda vez que la aceptación expresa de un inversor extranjero a la oferta de Bolivia a someterse a la jurisdicción del CIADI, debería haberse manifestado necesariamente antes de que Bolivia hubiera hecho efectiva la denuncia a la Convención de Washington.

Bolivia posicionaba como núcleo medular de su defensa que no existía forma que se cumpla con el consentimiento bilateral y escrito que exige el artículo 25 de la Convención de Washington, y por tanto se extrañaría el ineludible requisito exigido por la misma Convención para habilitar la jurisdicción del CIADI. Es decir que el CIADI habría dejado de ser un foro competente al

16. 700 millones de euros equivalen aproximadamente a USS 1.000 millones. 
haberse producido la denuncia de la Convención de Washington siguiendo las reglas y procedimientos establecidos en la propia Convención.

Este argumento parecía ser medio de defensa digno de intentarse habida cuenta que se auxiliaba de las normas contenidas en la misma Convención de Washington, no existiendo jurisprudencia o precedentes particulares sobre la denuncia y los efectos que ella produce. Esta defensa ofrecía a Bolivia la posibilidad de diferir el conocimiento del fondo de la controversia o al menos evitar un ingreso tan apresurado a la fase de averiguación de los méritos sobre la vulneración de los estándares de protección internacional a los que Bolivia se encontraba obligada en mérito al BIT entre Bolivia y los Países Bajos.

Sin embargo, al haberse allanado ambas partes al procedimiento establecido por la CNUDMI, la estrategia central de defensa del Estado de Bolivia se desvaneció irremediablemente, provocando la precipitación acelerada de los plazos y de las distintas etapas procesales del procedimiento arbitral, puesto que incluso los árbitros ya designados ante el CIADI continuarían ocupando sus cargos.

El verdadero efecto de los Acuerdos de la Ex Ministra Rocabado se traduce en la agilización del procedimiento contra Bolivia, cuyo eventual Laudo sobre los méritos de la controversia se emitiría también con mayor celeridad. La defensa principal del Estado de Bolivia fue defenestrada por los Acuerdos de Arbitraje Ad Hoc, sin que exista otra alternativa más que ingresar a dilucidar los méritos en los cuales ETI ha fundado su reclamación internacional.

Con los Acuerdos sobre Arbitraje Ad Hoc, Bolivia en el fondo sólo perdería valiosos tiempos y derechos importantes que la habilitaban para que, en el marco de un debido proceso, pueda objetar la jurisdicción de cualquier Tribunal Arbitral, habiendo dado pie a que la demanda en su contra se apresure al 
mismo tiempo que su cuantía se eleva en proporciones significativas y alarmantes por el impacto negativo que podrían tener en nuestra economía, por la posible disminución de Reservas Internacionales Neta que por el momento mantienen niveles adecuados gracias a las exportaciones de recursos hidrocarburíferos y minerales fundamentalmente.

\section{VIGENCIA Y EFICACIA DE LOS 22 BITS SUSCRITOS POR BOLIVIA}

Pero lo que resulta más alarmante es que los Acuerdos sobre Arbitraje Ad Hoc firmados por la plenipotenciaria de Bolivia, ni siquiera contribuirán con el bastión de defensa de rechazo a la jurisdicción del CIADI, toda vez que no servirán para argumentar que el CIADI deja de tener jurisdicción en cualquier controversia y para cualquier disputa sobre inversiones protegidas en la que el Estado se vea involucrado en calidad de demandado.

Prueba fehaciente de lo indicado en el párrafo anterior es que la compañía petrolera anglo-americana Pan American Energy LLC (PAE), misma que al igual que ETI sufrió la nacionalización de su paquete accionario en la Empresa Petrolera Chaco S.A. ${ }^{17}$, ha presentado una solicitud de arbitraje precisamente ante el CIADI, lo cual deja ver que los Acuerdos de Arbitraje Ad Hoc con ETI, bajo ningún fundamento, podrían ser considerados como una batalla ganada, y muy por el contrario, sólo constituyen una fuente de controversia que inclusive ha dado lugar a la persecución penal de la Ex Ministra de Defensa Legal del Estado, por atentar contra los altos intereses de Bolivia.

Los Acuerdos de Arbitraje Ad Hoc ni siquiera serían un avance para defenestrar la jurisdicción del CIADI, debido a que,

17. El paquete accionario de PAE fue nacionalizado por el Gobicrno del Presidente Evo Morales a través del Decreto Supremo No. 29887 de 23 de enero de 2009, emitido a sólo dos dias de la fecha marcada para el referendo constitucional para aprobar el proyecto de Constitución impulsado por el partido de Gobicrno y sectores afines al mismo. 
como se señaló anteriormente, los 22 BITs suscritos entre Bolivia $\mathrm{y}$ otros Estados permanecen inalterables en su contenido y vigencia, estando establecido en el clausulado de los mismos que ante el surgimiento de controversias relativas a inversiones de nacionales de otros Estados amparados por los BITs, éstos tendrían la facultad de acudir ante el CIADI o, si así lo decidiesen, activar el mecanismo fijado por la CNUDMI, cual ha ocurrido en el caso de ETI.

Vale decir que no obstante la denuncia de la Convención de Washington por parte del Estado de Bolivia, de todas maneras la jurisdicción del CIADI se encontraría reconocida por dicho Estado, mediante una serie de Tratados Internacionales (BITs) que a la fecha no han sido renegociados, manteniéndose por tanto vigentes y conservando por consiguiente plena eficacia jurídica, de acuerdo a las reglas de Derecho Internacional Público contenidas en la Convención de Viena sobre el Derecho de los Tratados. 